\title{
AIDS e pauperização: principais conceitos e evidências empíricas
}

\author{
AIDS and pauperization: \\ principal concepts and empirical evidence
}

Francisco Inácio Bastos 1

Célia Landmann Szwarcwald 1

\footnotetext{
1 Departamento de Informações em Saúde Centro de Informação Científica e Tecnológica, Fundação Oswaldo Cruz. Av. Brasil 4365, Rio de Janeiro, RJ 21045-900, Brasil.
}

\begin{abstract}
This paper discusses methodologies for analyzing relations between social inequalities, marginalization, prejudice, and vulnerability to HIV/AIDS, highlighting current difficulties and alternative research strategies. It al so reviews the international and Brazilian literature, emphasizing: economic and macropolitical dimensions in the spread of HIV/AIDS; the role of drug policies and consumption; gender inequalities and prejudice; racial/ethnic inequalities and prejudice; and interaction with other STIs and their relationship to poverty; HIV/AIDS and heal th care standards, especially access to antiretroviral therapy; and human rights violations. Despite current methodological dilemmas in analyzing relations between psychosocial, cultural, and soci opolitical variables and vulnerability to HIV/AIDS and thelimited Brazil literature, such themes merit further investigation, addressing Brazilian social and cultural specificities and profiting from recently devel oped research strategies.
\end{abstract}

Key words Acqui red Immunodefi ciency Syndrome; Poverty; Human Rights; Social Conditions

Resumo $\mathrm{O}$ artigo discute as estratégias metodológicas que vêm sendo usadas na análise das inter-relações entre a vulnerabili dade ao HIV/AIDS e as desi gual dades sociais, o preconcei to e a marginalização, ressaltando-se as dificuldades metodológi cas e as estratégi as al ternativas de investigação encontradas. Os principais achados da literatura internaci onal e brasileira foram revistos, enfatizando-se os temas: dimensões econômicas e macropolíticas da difusão do HIV/ AIDS; papel do consumo e da política de drogas; desigual dade e preconceito de gênero; desigual dade e preconcei to racial/origem étnica; interação com as demai s infecções sexual mente transmissívei s e sua relação com a pobreza; padrões de assi stência à saúde e HIV/AIDS, em especial, acesso a anti-retrovirais; eviolação dos direitos humanos. Apesar da restrita produção acadêmica brasi lei ra e dos dil emas metodológi cos envol vi dos no exame das inter-relações entre variáveis psi cossociais, culturais, sóci o-políticas e vul nerabilidade ao HIV/AIDS, tais temas devem ser investigados em detalhe - consi derando especificidades sociais e culturais do Brasil - e beneficiados pelas novas estratégi as de pesquisa.

Palavras-chave Síndrome da Imunodeficiência Adqui rida; Pobreza; Direitos Humanos; Condições Sociais 
A complexidade do marco conceitual e a "teia da causalidade"

A relação entre vulnerabilidade à infecção pelo HIV e iniqüidade social - analisada a partir de diferentes pontos de vista e abordagens metodológicas - apresenta-se como bastante vigorosa na literatura internacional, a despeito da extrema complexidade de sua avaliação empírica.

Uma tomada de posição - que nos parece imprescindível, ao revisar criticamente o conjunto de achados - é abrir mão, quase invariavelmente, de alguns pressupostos caros aos métodos habitualmente empregados nas ciências naturais. Em virtude da singularidade dos diversos contextos sócio-políticos e culturais em que a questão vem sendo analisada, é extremamente difícil, por exemplo, aspirar à replicabilidade e possibilidade de generalização dos achados.

Da mesma forma, em decorrência de questões éticas de vital importância, todos os estudos nesse campo são de natureza estritamente observacional, muitos del es envolvendo tempos longos (históricos). Utilizando a terminologia clássica de Dilthey (Wilhelm Dilthey - filósofo alemão - 1833-1911) na maior parte das vezes é possível "compreender" determinada associação, mas não "explicá-la" em termos de uma causalidade stricto sensu.

Feitas essas ressalvas, cabe assinalar que o propósito deste texto é rever, de forma sistemática, os diversos achados empíricos concernentes à questão, ainda que seja evidente a disparidade de marcos conceituais utilizados pelos diferentes autores. Vemos na literatura, por exemplo, que a desigual dade social é expressa mediante conceitos que não se inter-relacionam com facilidade tais como: classe social, segmento populacional e vizinhança geográfica. Sobressai - em particular, na literatura norte-americana - uma não-tematização e/ ou nãoexplicitação dos conceitos acima citados e a aparente "reunião" simplificadora destes sob a designação "origem étnica" (em mistura, freqüentemente pouco explícita, com a vertente mais biologizante de "raça"). Em que pese a evidente desigual dade da sociedade norte-americana (e também da brasileira) com relação às diferentes origens étnicas, há simplificação, por exemplo, na designação "latino", que combina desde americanos natos - como os porto-riquenhos ou os descendentes de uma ou mais gerações originárias da América Latina e Caribe - a nacionais de diferentes países inseridos formalmente na sociedade americana, além de imigrantes clandestinos e trabalhadores temporários.
Por isso, a nossa opção no presente texto é tematizar a questão da vulnerabilidade à infecção pelo HIV com relação a quaisquer "recortes" que traduzam desigual dades com dimensão coletiva e que possam resultar em possibilidades diferenciadas quanto ao usufruto de bens e serviços tanto materiais (como habitação, alimentação adequada e tratamento médico) como simbólicos (utilizamos aqui, de forma relativamente livre, conceitos de Pierre Bourdieu, sociólogo francês que superou a direcionalidade das díades marxistas infra-estrutura/ superestrutura e/ ou bens materiais/culturais, em que os primeiros termos das díades precediam e determinavam os segundos, abrindo espaço para uma bidirecionalidade entre bens materiais e simbólicos - e a idéia de uma "economia das trocas simbólicas" -, como informação e poder de se autodeterminar). Esta nos parece uma alternativa válida frente à predominância maciça dos estudos que consideram relevantes exclusivamente as variáveis explicativas individuais, e o indivíduo como único nível a ser focalizado pelas intervenções preventivas. Embora a dimensão individual seja irredutível, uma vez que sempre existe margem ao arbítrio dos indivíduos singulares em meio às representações coletivas e mudanças comunitárias e estruturais, é sempre possível atuar em diferentes níveis, tendo em mente que as mudanças estruturais - envolvendo comunidades e, mesmo, culturas - atingem simultaneamente grande número de pessoas e podem persistir por gerações (Yen \& Syme, 1999).

Um fato preocupante nesta predominância absoluta de modelos de análise exclusivamente individuais é que estes se mostram imprecisos e incompletos, ainda que não se leve em conta a dimensão propriamente social da questão, mas tão somente a biologia do agente infecioso (o HIV) nas populações humanas. Neste sentido, cada indivíduo é simultaneamente alguém mais ou menos vulnerável à infecção pelo HIV e alguém inserido em uma comunidade ou segmento populacional que possui maiores ou menores "prevalências de fundo" (background prevalences). Exemplo claro disso é o trabalho de Friedman et al. (1995), autores que demonstraram que os principais fatores de risco para a infecção pelo HIV entre usuários de drogas injetáveis (UDI) eram distintos em função da inserção dos UDI em comunidades com taxas mais ou menos elevadas de infecção pelo HIV.

Além disso, inúmeros trabalhos documentam o papel exercido pelas demais infecções sexualmente transmissíveis (IST) - utilizamos aqui a designação infecções sexualmente transmissíveis (IST) em substituição à designação 
mais tradicional "doenças sexual mente transmissíveis" (DST), uma vez que diversas infecções não determinam quadros clínicos evidenciáveis, nem por isso deixando de determinar maior vulnerabilidade à infecção pelo HIV. Tal terminologia foi consagrada na última edição de AIDS in theWorld (II), de 1996 - no que se refere ao aumento dos riscos de infecção pelo HIV (Eng \& Butler, 1997) e analisam o papel central das IST na dinâmica do HIV em populações humanas (Boily \& Anderson, 1996). Aqui se repete o problema anterior, visto que diferentes segmentos populacionais possuem distintas "prevalências de fundo" dos agentes das IST, além de "padrões de mistura" (mixing patterns) específicos entre indivíduos e grupos.

Outra questão central - não tematizada pelos estudos desenvolvidos exclusivamente ao nível individual - é a da complexidade e diversidade dos resultados em função das unidades e do nível de agregação das análises, que, para além dos sujeitos singulares, podem ter como objeto desde díades de parceiros e redes sociais (Morris et al., 1995; Friedman et al., 1998) até estados nacionais ou continentes (Farmer, 1996; Mann \& Tarantola, 1996), passando por comunidades de diferentes dimensões e composições (Wallace \& Wallace, 1995).

Em anos recentes, o progresso metodológico quanto à análise de efeitos contextuais e mensuração de estruturas de interação social tem sido expressivo. Duas estratégias metodológicas vêm sendo aplicadas no âmbito da saúde pública com resultados significativos. Além dos métodos de análise das redes sociais (Barbosa et al., neste fascículo), a utilização de modelos hierárquicos ou técnicas de análise em múltiplos níveis tem permitido analisar simultaneamente variáveis individuais e contextuais, sem incorrer na tradicional imprecisão epistemológica decorrente da mistura de nexos causais de níveis distintos (proximais e distais) (Wong \& Mason, 1991).

Habitualmente, a dimensão propriamente coletiva é considerada, de forma simplista, como não-mensurável e, mais do que isso, como externa ao campo propriamente científico. Além disso, os fatores não-individuais, ao serem compreendidos - de forma acertada - como estruturais, são vistos como - de forma equivocada - impermeáveis a quaisquer mudanças (Tawil et al., 1995).

Como discutido recentemente por Mattos (1999), diversas relações de natureza supostamente causal têm sido estabelecidas entre a implementação de ações preventivas e alterações subseqüentes nos dados epidemiológicos, sem atentar a complexa dinâmica intrínseca da epi- demia de HIV/AIDS e sua múltipla determinação. Somente a partir de amplo conjunto de informações oriundas de análises realizadas em diversos níveis e levando em conta variáveis que vão desde a biologia e o psiquismo individual à estrutura sócio-econômica e às culturas, será possível estabelecer os reais fundamentos de avaliações da efetividade das ações preventivas e terapêuticas ao nível da saúde coletiva.

Como se não bastassem os desafios conceituais e metodológicos já apontados, mencionaremos um último (apenas na medida em que não nos move nenhum propósito de exaustividade). Tanto do ponto de vista das comunidades definidas do ponto de vista geográfico como dos segmentos populacionais, há importante superposição de iniqüidade social e agravos à saúde.

Da perspectiva das comunidades geográficas, é comum que áreas mais pobres conjuguem inúmeros fatores adversos no que diz respeito à falta de infra-estrutura, baixa oferta de serviços e oportunidades de emprego, ou à possibilidade restrita de atendimento das suas demandas face às restrições das políticas públicas e orçamentos (Wallace \& Wallace, 1995), que se somam aos efeitos sobre os padrões de morbi-mortalidade diretamente decorrentes da agregação de pessoas com baixa renda em determinado espaço (Massey, 1996).

Esta multiplicidade de problemas e dificuldades está associada, com freqüência, a um conjunto de problemas e agravos, tais como: índices elevados de consumo de álcool e drogas, violência estrutural e alta prevalência de infecções sexualmente transmissíveis, todos eles fatores de aumento da vulnerabilidade à infecção pelo HIV através de intermediações diversas, que vão do biológico (como no casos das IST) às limitações impostas à sistematicidade e abrangência das ações de prevenção em função dos elevados níveis de violência em determinadas comunidades (Zierler \& Krieger, 1997). Rodrick Wallace e colaboradores, em diversos trabalhos (Wallace \& Wallace, 1995; Wallace et al., 1996; Wallace et al., 1997, entre os mais recentes) vêm demonstrando o caráter sinérgico desses agravos e problemas sociais, para os quais Merrill Singer cunhou o termo "sindemia” (Singer, 1994). Existe aí, portanto, uma complexa rede de determinações que torna difícil, se não impossível, a identificação e mensuração do papel de cada um dos fatores envolvidos (Krieger, 1994).

A conclusão semelhante chegaremos se olharmos a questão da vulnerabilidade à infecção pelo HIV a partir de segmentos populacionais sob risco especial. Nestes segmentos igual- 
mente interagem, de forma sinérgica, problemas de diversas ordens, como, por exemplo, entre os usuários de drogas injetáveis pertencentes aos estratos mais pobres, envolvidos na prática do sexo comercial e/ ou inseridos no pequeno tráfico e outras atividades ilícitas, visando financiar seus hábitos de consumo (Friedman et al., 1998; Szwarcwald et al., 1998), combinando os efeitos adversos das políticas de controle de drogas (como veremos em item específico, a seguir), representações sociais estigmatizantes (incluindo racismo e discriminação de gênero, ou em decorrência de hábitos ilícitos e/ ou estigmatizados) e parâmetros econômicos (precariedade de inserção no mercado formal, riscos decorrentes da participação em atividadesilícitas). Em suma, também aqui existe interação de diversos fatores de atuação mais proximal ou distal (Victora et al., 1997), no sentido de fazer com que estes segmentos sejam mais vulneráveis à infecção pelo HIV.

Portanto, as seções subseqüentes abordarão a questão da vulnerabilidade social ao HIV/AIDS segundo os eixos principais de análise, com o propósito exclusivo de simplificar a apresentação, mas sem qualquer pretensão de singularizar determinados fatores ou abordar o conjunto de fatores de forma exaustiva.

\section{Dimensões macroeconômicas e macropolíticas}

Um número reduzido de autores têm pensado a questão da vulnerabilidade social e a conseqüente pauperização da epidemia de AIDS em termos macroeconômicos e macropolíticos. O pioneirismo cabe aqui à equipe de Jonathan Mann (Mann \& Tarantola, 1996), tanto no antigo Programa Global de AIDS como na Universidade de Harvard.

Hoje, uma das perspectivas críticas mais consistentes - não só em relação à difusão seletiva do HIV/ AIDS nos estratos mais pobres, mas à (re)emergência de amplo conjunto de patógenos - é a de Paul Farmer (1996, 1997). Farmer tem incorporado uma dimensão de ecologia social aos modernos estudos acerca da ecologia das doenças infecciosas, ou seja, compreende ele a emergência, reemergência e disseminação seletiva dos patógenos como não apenas tributárias da biologia evolucionista e da ecologia dos agentes infecciosos, mas também dos impactos da iniqüidade social e da violência estrutural, esta última em acepção bastante ampla (que incorpora não apenas a violência em sentido específico, mas quaisquer violações dos direitos humanos). Em outras palavras, não existiria propriamente uma ecologia "natural" em se tratando de populações humanas, sendo esta, invariavelmente, biológica e social (por diversas razões que expomos no presente texto).

As variáveis sociais determinariam sempre alterações na ecologia das doenças infecciosas, ou seja, estratos mais pobres e menos assistidos tornam-se mais vulneráveis à difusão destes agentes por razões predominantemente biológicas (como pior imunidade), predominantemente sociais (menor capacidade de ter suas demandas atendidas, residência em locais com infra-estrutura precária), no mais das vezes por razões, simultaneamente, sociais e biológicas.

Perspectiva complementar à citada é a de que estes segmentos se deparam também com barreiras estruturais quanto à possi bilidade de implementar e manter mudanças que minimizam os riscos de se infectar (Tawil et al., 1995). Estas barreiras são inúmeras, incluindo: indisponibilidade de recursos essenciais à prevenção (como preservativos ou seringas estéreis) devido a barreiras culturais, falta de recursos, situações de constrangimento subjetivo e objetivo de natureza diversa (a título de exemplo, pensemos na precariedade e nos riscos presentes nos locais de consumo de drogas); dificuldade de acesso a serviços de prevenção e tratamento; impossibilidade de implementar politicamente decisões comunitárias; menor escolaridade e menor domínio da linguagem escrita, o que cria obstáculos ao acesso a informações atualizadas; maiores dificuldades na manutenção de comportamentos preventivos ao longo do tempo pela pressão permanente de ameaças concretas e prementes como o desemprego, os problemas de moradia ou a fome.

O ponto de vista mais polêmico talvez seja o de Lurie et al. (1995), que identifica fatores fundamentais à disseminação do HIV/AIDS nos assim denominados "ajustes estruturais", propostos e monitorados por organismos internacionais, alguns deles envolvidos no próprio financiamento das ações de saúde nos países em desenvolvimento. Através da restrição dos gastos públicos (e suas conseqüências adversas sobre as políticas sociais), precarização do mercado de trabalho etc., estabelecer-se-ia um contexto propício à maior vulnerabilidade (pelas razões que discutimos ao longo deste texto) frente à infecção pelo HIV nas comunidades sujeitas a tais ajustes. Tal formulação, principalmente por incluir organismos que vêm atuando de perto no financiamento das ações de diversos Programas Nacionais de Controle das IST e da AIDS, deu origem a ácidos debates que estão longe de terminar. 
Efeitos adversos do consumo de drogas e das políticas de drogas

Não detalharemos aqui, por tê-lo feito em momento anterior (Bastos, 1996), os efeitos adversos do consumo de drogas - em particular, por via injetável - e das próprias políticas de drogas (as quais, destinadas a coibir este consumo, acabam, muitas vezes, por determinar problemas adicionais, como discutimos a seguir). Cabe observar que o uso comum de equipamentos de injeção constitui um dos meios mais eficientes de transmissão do HIV e demais patógenos de transmissão sangüínea. Em grande medida, tais riscos adicionais são determinados pelos efeitos adversos da própria política de drogas, que, por exemplo, restringe o acesso aos equi pamentos de injeção em diversos países, criminaliza sua posse e faz com que boa parte do consumo se dê em locais improvisados, em condições obviamente não-higiênicas, supostamente inacessíveis às forças policiais encarregadas de reprimir tais práticas (Wodak, 1998).

O consumo de drogas constitui o único hábito/ comportamento relacionado ao risco de infecção pelo HIV que é não só objeto de estigmatização (comum a outros hábitos/ comportamentos vinculados ao risco de se infectar com o HIV, tais como as relações homossexuais masculinas), mas de criminalização. Por isso mesmo, padrões de consumo grosso modo comparáveis - como os de Nova York, EUA e Roterdã, Holanda - podem dar origem a "cenas de uso" inteiramente distintas (Grund et al., 1992), com taxas de infecção pelo HIV entre os UDI e seus parceiros também bastante distintas. Existe aí marcada superposição entre locais em que a saúde pública constitui o eixo das políticas de drogas - onde foram desenvolvidos precoce e amplamente programas de prevenção - e taxas mais baixas de infeção pelo HIV (Des Jarlais \& Friedman, 1998).

De modo geral, os UDI pertencem aos estratos mais desfavorecidos da sociedade, tanto pelo fato de maior número de pessoas de camadas mais pobres se utilizarem de drogas ilícitas de forma mais grave e geradora de danos, quanto em decorrência da precária inserção social e profissional de boa parte daqueles usuários de drogas que se engajaram nestas formas graves de consumo. Como dissemos acima, tais efeitos adversos se intensificam nos contextos em que as políticas de drogas são mais repressivas e estigmatizantes.

$\mathrm{Na}$ epidemia norte-americana evidenciouse, desde o início, o fato dos UDI pertencerem a estratos sócio-econômicos mais baixos e contribuírem substancialmente para a "pauperização" da epidemia, como um todo, à medida que crescente número de casos de AIDS foi sendo registrado entre UDI e seus parceiros sexuais (Friedman et al., 1987).

No Brasil, a participação proporcional dos UDI el evou-se substancialmente ao longo de toda a década de 80 , estabilizando-se na presente década. Também entre nós, os UDI pertencem majoritariamente aos estratos sociais mais pobres, menos escolarizados e residem geral mente em áreas mais pobres das cidades (Grangeiro, 1994; Fonseca \& Castilho, 1997). Na medida em que são, em sua maioria, homens, jovens, sexualmente ativos e com uso sistemático de preservativos bastante reduzido (Telles et al., 1997), desempenham papel relevante na disseminação subseqüente da infecção para suas companheiras (UDI ou não, havendo, no primeiro caso, duplo risco de infecção, já que, com freqüência, as mulheres que injetam drogas, fazem-no em comum com seus parceiros Friedman et al., 1998) e prole, especialmente nas comunidades em que a população de UDI é de tamanho substancial.

\section{Desigualdades e discriminação de gênero}

As inter-relações entre desigual dade sociais, de modo geral, e desigual dades e discriminação de gênero permeiam debates da agenda social e política contemporânea (Mongella, 1995). A despeito do inevitável reducionismo, optamos aqui por sublinhar apenas aqueles aspectos mais diretamente vinculados à ampliação dos riscos de infecção pelo HIV das mulheres, sem duplicar tópicos abordados nos demais itens (Zierler \& Krieger, 1997).

As mulheres são mais vulneráveis à infecção pelo HIV do ponto de vista biológico. A superfície da mucosa vaginal exposta ao sêmen é relativamente extensa, e o sêmen tem concentração de HIV (livre e no interior das células) significativamente maior do que o líquido vaginal (Chiriboga, 1997; Coll et al., 1999). Além disso, as IST são mais freqüentemente assintomáticas na mulher do que no homem (Eng \& Butler, 1997), e o fato de não terem dimensão clínica evidente não significa que, através de inflamação local e micro-lesões, não determinem fragilização das barreiras naturais à infecção pelo HIV. Estes riscos ampliados de exposição à infecção pelo HIV se acentuam nas mulheres mais jovens, pré-púberes e adolescentes jovens, nas quais a imaturidade do aparelho genital determina fragiliza- 
ção adicional frente à infecção pelo HIV (Chiriboga, 1997; Coll et al., 1999).

Epidemiologicamente, as "regras" de pareamento entre os gêneros de óbvia determinação sócio-econômica e cultural, vigente na ampla maioria das sociedades tanto dos países desenvolvidos como em desenvolvimento, fazem com que mulheres mais jovens mantenham habitualmente relações sexuais e estabeleçam parcerias com homens mais velhos. Com isso, coortes etárias mais jovens de mulheres estão sob risco ampliado de se infectarem com o HIV (e demais IST) ao fazerem sexo desprotegido com um pool de homens (mais velhos) que apresentam níveis de prevalência para o HIV (e demais IST) mais elevados. Além das repercussões diretas na população feminina, esta assimetria de pareamento determina epidemias mais extensas e mais dilatadas no tempo, se comparadas a uma epidemia hipotética em comunidade na qual vigorasse o pareamento simétrico (Gupta et al., 1989).

Mas a questão central aqui é que os dois gêneros, a despeito de inúmeras iniciativas, são tratados desigualmente em termos políticos, culturais e sócio-econômicos. Estes eixos de desigualdade apresentam simultaneamente dimensão macro e microssocial, ou seja, a observância ou não dos direitos, as relações desiguais de poder e o acesso diferenciado a bens materiais e simbólicos têm lugar tanto no âmbito das parcerias e famílias como da sociedade ou das culturas nacionais e supranacionais (organizadas, por exemplo, em sistemas de crença e códigos de valores). Com freqüência, desigualdades presentes em instâncias diversas se superpõem, gerando efeitos sinérgicos, como nos múltiplos riscos a que estão submetidas muIheres de países em desenvolvimento onde existe marcada desigualdade de gênero. A título de exemplo, citamos a violência sexual dirigida às mulheres, adolescentes e crianças do sexo feminino na África do Sul (Leclerc-Madlala, 1997), ou a profunda dependência econômica das mulheres de diversos países do sudeste da Ásia (M boi, 1996). A combinação da violência material e simbólica da "dupla moral" - no que diz respeito ao comportamento sexual de homens e mulheres no âmbito da família e da sociedade -, da assimetria na capacidade de tomar decisões e de efetivá-las, bem como a ausência de canais para a manifestação de queixas e resolução de pendências - pelo diálogo ou via legal -, faz com que para as muIheres seja mais difícil ter acesso a informações adequadas e atualizadas; uma vez que estas sejam obtidas, é penosa a modificação de comportamentos e, mesmo que venham a ser alte- rados, a dificuldade instaura-se na manutenção de tais mudanças nas interações cotidianas.

Representações sociais que consubstanciam a desigual dade de gênero permeiam não só o imaginário leigo, mas também, infelizmente, o dos profissionais de saúde que estariam supostamente a cargo de, por exemplo, identificar parceiros de casos-índice, orientar tratamentos muitas vezes conjuntos e aconsel har indivíduos e casais a adotarem comportamentos seguros. Como Giffin \& Lowndes (1999) demonstraram recentemente, tais procedimentos não são feitos de forma adequada do ponto de vista científico e da perspectiva de uma cultura que não se queira sexista e paternalista, incidindo preferencial mente sobre mulheres de classe mais pobres, "infantilizadas" por orientações e aconselhamentos incompletos e errôneos. Portanto, do ponto de vista das intervenções preventivas desenvolvidas por profissionais, as mulheres pobres não se beneficiam, como deveriam, das melhores práticas disponíveis, que possibilitariam compensar, ao menos em parte, a maior vulnerabilização dessa popuIação frente à infecção pelo HIV e demais IST.

Além dos fatores de aumento da vulnerabilidade propriamente ditos, uma questão suplementar diz respeito à pequena disponibilidade de métodos de prevenção controlados (ou ao menos "iniciados") pelas mulheres. Por um lado, os viricidas de utilização tópica no aparelho genital feminino ainda são controversos, não representando, por ora, alternativa real mente efetiva em termos populacionais (van Damme \& Rosenberg, 1999). Por outro, há inquestionável incremento no uso do condom feminino, mas ainda restrito basicamente às camadas mais ricas (já que o preço ainda é elevado), que dispõem de maior informação e em parcerias e contextos culturais mais receptivos à inovação e à iniciativa feminina (Elias \& Coggins, 1996). Ou seja, também em relação aos métodos preventivos existe assimetria de acesso e aceitabilidade que, quase invariavel mente, incide negativamente sobre as camadas sociais mais pobres.

\section{Desigualdades e discriminação étnica/racial}

Na produção acadêmica que tematiza a raça/ origem étnica e/ ou classe social como variáveis a serem analisadas quanto à pauperização da epidemia em diferentes contextos, existe uma "tensão" a ser explicitada, ainda que sem qualquer preocupação de discutir a questão dos conceitos de raça/ origem étnica em si . 
Por um lado, inúmeros autores norte-americanos (como Rosenberg, 1995 ou Greenland et al., 1996), ao analisarem as tendências, inequívocas, de pauperização da epidemia de AIDS naquele país, "recortam" a população segundo sua origem étnica. Por outro lado, na literatura brasileira, mesmo considerando sua natureza fragmentária, praticamente não há menção a esta variável, como se, uma vez estratificados os dados por indicadores sociais como escolaridade, ocupação ou local de moradia -, não sobrasse espaço para características ligadas à origem étnica - como os padrões culturais dos diferentes segmentos populacionais, definidos também a partir da origem étnica - e ao manifesto preconceito dirigido a diversos destes segmentos.

O artigo de Rosenberg (1995) a respeito da magnitude e tendências da epidemia norte-americana foi objeto de debate na revista Science exatamente acerca da questão da raça/ etnia. Dois comentadores desse trabalho (Males, 1996; McMillan, 1996) mencionaram o fato de que "ponderando" os estratos sociais "recortados" segundo origem étnica pela utilização da variável renda (definida, no caso, como percentagem de pessoas abaixo da linhade-pobreza), o peso da origem étnica como variável explicativa da pauperização "desapareceria”, uma vez que não há qualquer plausibilidade biológica que explique a maior vulnerabilidade frente à infecção pelo HIV observada entre as populações de negros e latinos.

A resposta de Rosenberg reconhece a relevância das críticas, observando, no entanto, que tanto em relação à hepatite $\mathrm{B}$ como ao HIV/ AIDS, ainda que se proceda às necessárias ponderações por indicadores referentes ao status sócio-econômico, existe sempre um "resíduo" de maiores taxas de incidência (desfavorável às populações negras e latinas), de magnitude variável. Este resíduo poderia ser explicado de três maneiras (duas delas - "a" e "c" - mencionadas por Rosemberg):

a) diferenças entre os segmentos populacionais não redutíveis ao status sócio-econômico, e supostamente vinculadas à influência das culturas (mediadas, entre outras coisas, pela origem étnica) sobre os comportamentos individuais e padrões de interação de parcerias e grupos;

b) efeito das interações no âmbito de determinadas redes sociais, que seriam constituídas por laços sociais determinados, simultaneamente, pelo status sócio-econômico similar e background étnico similar, redes estas não só com padrões comportamentais e de interação distintos, como também com níveis de preva- lência distintos para a infecção pelo HIV (e demais IST), ou, alternativamente;

c) à incapacidade de o conjunto de indicadores utilizados (nesta e outras pesquisas) traduzirem, de forma precisa, o status sócio-econômico. No âmbito dos estudos norte-americanos não parece haver dúvida de que a discriminação racial determina padrões de segregação residencial e distribuição desigual de pessoas, em diversas instituições e empresas, com base na sua origem étnica/ racial (Yen \& Syme, 1999), com óbvias conseqüências sobre a natureza das interações sociais e do acesso a recursos materiais e de poder.

Ampliando a discussão e trazendo-a para o contexto brasileiro, cabe, por um lado, desenvolver estudos acerca dos padrões de interação sexual e de consumo de drogas em diferentes comunidades, procurando compreender as conseqüências, para a disseminação do HIV/AIDS, da concentração em determinado locais de pessoas de status sócio-econômico similar e, simultaneamente, de determinada origem étnica. É necessário, nesse sentido, deixar de lado a habitual indiferença da pesquisa brasileira quanto à análise da desigualdade social segundo estratificação étnica/ racial, evidenciada, por exemplo, na Pesquisa de Padrão de Vida (PPV), que mostrou que chefes de família de escolaridade equivalente recebiam remunerações médias com variações de praticamente $100 \%$ em detrimento de negros e pardos, quando comparados aos chefes de família brancos (Sant'Anna, 1998).

Focalizando a questão mais específica da disseminação do HIV/AIDS, há evidências de que a população negra brasileira está mais sujeita às conseqüências adversas da violência estrutural (Pinho, 1998) presente nas comunidades faveladas e/ ou pontos de tráfico e venda de drogas, situação com conseqüências negativas óbvias sobre a continuidade de projetos de prevenção nestas comunidades e favorecedoras de uma maior "exposição" à oferta de drogas ilícitas e aos danos daí decorrentes (Wallace et al., 1996).

Desigualdade social e sua influência sobre a incidência e prevalência das IST

O papel das IST como fatores de risco centrais à infecção pelo HIV está hoje estabelecido de forma inequívoca (Eng \& Butler, 1997). Não resta dúvida também de que as IST são mais comuns entre os segmentos populacionais mais pobres, em razão de fatores similares aos expostos ao longo deste texto com relação à infecção pelo HIV/AIDS. 
Uma vez, no entanto, que a epidemiologia das IST guarda certas especificidades frente à do HIV/ AIDS, sublinharemos algumas dessas características a seguir. De qualquer modo, cabe observar que é difícil distinguir, ao nível das comunidades - embora tal distinção seja bastante nítida, no âmbito individual, tanto em experimentos biológicos como em estudos observacionais -, os efeitos específicos das IST sobre a disseminação do HIV/ AIDS e a influência de fatores comportamentais que são comuns à dinâmica das IST, de modo geral, e ao HIV/AIDS, em particular (padrões de interação sexual, uso de preservativos etc.).

Cabe sublinhar que, sendo as IST, na verdade, um grupo bastante heterogêneo de infecções (que inclui o HIV/ AIDS), existem particularidades que dizem respeito, por exemplo, às IST de origem bacteriana, mas não àquelas de origem viral. Enquanto para estas últimas o tratamento curativo de fato é bastante restrito, para as IST de origem bacteriana, a não ser que se trate de infecções por cepas resistentes, o tratamento é, de modo geral, eficiente e relativamente rápido. Com isso, é comum a ocorrência de diversos episódios das mesmas IST bacterianas em certos grupos populacionais. $\mathrm{O}$ pronto acesso a recursos diagnósticos e terapêuticos determina impacto fundamental sobre a epidemiologia das IST bacterianas, e este acesso é obviamente diferenciado nos diferentes segmentos populacionais.

Já as IST de origem viral estão freqüentemente associadas a quadros graves de evolução relativamente lenta, como na gênese do câncer uterino (secundário à infecção pelo HPV - vírus do papiloma humano) e do câncer hepático (secundário à hepatite $\mathrm{B}$ ). No entanto, o nexo causal entre a infecção original e o aparecimento do tumor é muito mais raramente estabelecido pelos pacientes acometidos - e, infelizmente, também pelos profissionais de saúde - do que no caso da infeção pelo HIV em reIação à AIDS. Com isto, tais infecções têm seu impacto subdimensionado e não são objeto da devida preocupação, em particular, entre os mais pobres.

Remetendo o leitor ao excelente trabalho editado por Eng \& Butler (1997), mencionaremos apenas mais duas particularidades de determinadas IST frente ao HIV/AIDS:

- As IST, cujas conseqüências básicas e/ou iniciais têm lugar no aparelho reprodutor, apresentam quadros clínicos com características bastante diversas em homens e mulheres. Somando-se a isso todas as questões discutidas nos itens anteriores, teremos dinâmicas bastante distintas de acordo com os gêneros, e as interações entre eles, e impactos complexos na dinâmica do HIV/AIDS;

- Nas IST bacterianas, o tratamento sintomático inadequado (errôneo ou por demais breve) pode dar lugar a quadros crônicos ou reincidentes e ao desenvolvimento de cepas resistentes. A literatura é unânime em apontar que segmentos mais desfavorecidos têm acesso a serviços diagnósticos e terapêuticos de pior qualidade e menor resolutividade e/ ou recorrem a instâncias externas ao sistema formal de saúde, muitas vezes de competência duvidosa.

Entre a infecção pelo HIV e a AIDS e depois - acesso diferenciado ao tratamento

A terapia anti-retroviral (AR) de alta potência e, em escala algo menor, a profilaxia para doenças oportunistas, como a pneumocistose, vêm determinando profunda reformulação na clínica e na epidemiologia da infecção pelo HIV/ AIDS. Iniciadas basicamente nos países desenvolvidos, em momentos cada vez mais precoces da infeção pelo HIV, têm aumentado substancialmente o intervalo de tempo entre a infecção pelo HIV e o aparecimento da síndrome clínica (AIDS). Estas terapias tornaram o registro exclusivo dos casos de AIDS um indicador bastante menos preciso e substancialmente mais defasado no tempo da dinâmica da disseminação do HIV em dada comunidade (ver revisão em Weidle et al., 1999).

Além disso, tais terapias vêm tendo impacto profundo sobre a história natural da infecção pelo HIV - alterando a natureza e a freqüência das doenças oportunistas e aumentando substancialmente a sobrevida das pessoas com AIDS.

No que se refere à pauperização da epidemia da AIDS, cabe observar que o acesso diferenciado aos $A R$, por razões que detalharemos a seguir, faz com que proporcionalmente mais casos de AIDS (caso partíssemos de um número hipoteticamente equivalente de novas infecções entre segmentos com maior e menor acesso aos AR) sejam notificados entre as camadas desfavorecidas, uma vez que a infecção pelo HIV progride para a AIDS mais rapidamente entre elas. Ou seja, é possível incorrer em erro ao afirmar que existe um processo, em curso, de pauperização da epidemia pelo HIV com base exclusivamente no fato de haver aumento do número de novos casos de AIDS entre estratos sociais mais pobres (enfim, é possível estar em curso um processo de disjunção temporal das "duas epidemias": a de HIV e a de AIDS). 
$\mathrm{Na}$ verdade, a questão do acesso desigual aos AR de alta potência aprofunda tendências anteriores de acesso diferenciado ao tratamento anti-retroviral de menor eficácia, porém mais barato e de monitoramento mais simples, e de sobremortalidade das camadas mais pobres, ainda que tendo garantido acesso igualitário às melhores práticas terapêuticas então disponíveis, como no sistema de saúde canadense (Hogg et al., 1994).

Atualmente poderíamos, grosso modo, compreender as dificuldades de acesso aos AR de alta potência sob duas perspectivas:

a) a falta de acesso global, em um país ou região, determinada pelos altos custos da terapia e/ ou não priorização desta medida no âmbito das políticas públicas. Inclui-se, neste caso, a esmagadora maioria das nações, segundo uma perversa lei de maior acesso em regiões com epidemias de AIDS de menor magnitude e maior PIB per capita (com a honrosa exceção do Brasil, país com epidemia de grande magnitude e PIB per capita médio) (Hogg et al., 1998);

b) a falta de acesso de determinados segmentos populacionais ao tratamento, ainda que este esteja disponível à população como um todo. Inclui-se neste caso o acesso problemático dos UDI ao tratamento, mesmo em um sistema de saúde com cobertura universal; ainda uma vez o exemplo é o Canadá (Strathdee et al., 1998).

A pior situação, em se tratando de países desenvolvidos, parece ter lugar entre os UDI norte-americanos, os quais, via de regra, não estão cobertos por seguros-saúde e são sabidamente esquivos em relação ao sistema formal de saúde, além de estigmatizados por este sistema (Celentano et al., 1998). De uma perspectiva mais abrangente, mesmo segmentos populacionais com escolarização e perfil profissional sofisticados, como os homens que fazem sexo com outros homens, brancos, de classe média alta, acompanhados pelo estudo multicêntrico MACS (em diversas cidades dos EUA) vêm-se deparando com problemas de perda de status profissional e renda à medida que seus quadros clínicos se agravam e seus tratamentos se tornam mais complexos e dispendiosos (Kass et al., 1994). Ainda que não comparáveis a populações de antemão empobrecidas, como os supracitados UDI, estes segmentos igualmente se vêem às voltas com maior dificuldade de pagar seus seguros privados e de prover seu sustento e/ ou tratamento, à medida que passam a necessitar crescentemente de suas poupanças e passam a auferir rendas menores em virtude de limitações impostas ao pleno exercício profissional e/ ou estigmatização decorrente de sua condição clínica.

Quanto aos países em desenvolvimento, a situação claramente pior tem lugar nos países da África subsahariana, onde a epidemia é de grande magnitude e os recursos são escassos mesmo para as ações básicas. Nestes últimos ocorre um processo real de pauperização progressiva das "duas" epidemias (HIV e AIDS), uma vez que mais casos de infecção pelo HIV vêm sendo registrados entre as camadas mais pobres dos países mais pobres e, uma vez infectadas, essas pessoas evoluem para quadros clínicos mais graves e para o óbito mais rapidamente. Esta situação é dramaticamente ilustrada pelas epidemias recentes em diversas regiões da Índia (Islam et al., 1999) e nos antigos "enclaves étnicos" (ainda hoje, comunidades de extrema miséria) da África do Sul (LeclercMadlala, 1997).

Violações dos direitos humanos e sua influência sobre a dinâmica da epidemia do HIV/AIDS

A relação entre os Direitos Humanos (e sua violação) e a saúde ultrapassa em muito o escopo do presente texto. Mesmo no âmbito específico da epidemia da AIDS, as formulações de Jonathan Mann (por exemplo, em Mann, 1998) e seu grupo de trabal ho apontam em várias direções que não abordaremos aqui.

De forma sucinta, diríamos que as violações dos direitos humanos incidem particularmente sobre aqueles que, em função de iniqüidades sociais de várias naturezas e determinadas por pertencimento a certa classe social ou gênero, opção sexual, religiosa etc., são objeto de estigmatização e/ ou têm menor acesso aos meios/vias de afirmação/ recuperação de seus direitos.

A temática do direitos humanos e saúde recobre as questões abordadas nos itens anteriores, compreendendo violações mais evidentes à saúde física e mental - como no abuso sexual ou violações mais genéricas e indiretas - quando, por exemplo, a violação ao direito de associação e livre expressão faz com que determinado grupo não possa se reunir para discutir estratégias comuns de prevenção ou implementar determinadas estratégias.

De uma perspectiva mais ampla, cabe reconhecer o direito à saúde como um dos direitos mais fundamentais dos seres humanos e entendê-la segundo um marco conceitual não-reducionista, ou seja, de que não é possível promovê-la sem que condições mínimas de nutri- 
ção, acesso à moradia, educação e emprego sejam garantidas. Ou seja, é exatamente pela não garantia a estes direitos e sua violação sistemática que são engendrados quadros de desigualdade de natureza vária, a serem parcialmente compensados pela atuação de políticas públicas, grupos de defesa dos direitos humanos, entidades não-governamentais etc. Como as desigual dades a serem enfrentadas ultrapassam, em muito, os recursos materiais e humanos dessas instituições e grupos, e como há constrangimentos de natureza estrutural e histórica consubstanciados na exploração econômica, no racismo, no sexismo etc., não existe expectativa, a curto e médio prazo, de reversão das ten dências presentes de maior vulnerabilidade à infecção pelo HIV (entre inúmeros outros agravos), de assimetrias profundas na dinâmica da epidemia e, igualmente, de marcadas assimetrias no que diz respeito ao acesso a recursos preventivos e terapêuticos.

Um exemplo que se tornou paradigma no enfrentamento da epidemia da AIDS é a resposta das comunidades gays organizadas em diferentes sociedades, todas elas permeadas por representações e reações homofóbicas, ou seja, de discriminação em função da opção sexual, no caso, de homens que fazem sexo com outros homens. Ao contrário de uma visão simplista que compreende tanto a dinâmica da epidemia nesta população como a dinâmica de

\section{Agradecimentos}

Linha de trabalho financiada pelo Ministério da Saúde, Conselho Nacional de Desenvolvimento Científico e Tecnológico - CNPq e Fundação de Amparo à Pesquisa do Estado do Rio de Janeiro - FAPERJ. Este trabalho foi financiado pela Coordenação de DST e AIDS do Ministério da Saúde. seu enfrentamento através da mobilização comunitária de forma linear, o que existe, de fato, é uma interação complexa de forças favoráveis e contrárias a estas iniciativas coletivas.

É na interação entre preconceito e advocacia dos direitos das minorias, violação dos direitos humanos e superação desses constrangimentos mediante a auto-organização, a mobilização cultural e política etc. que se define um quadro multifacetado, o qual faz com que, por exemplo, a situação de comunidades gays, brancas e afluentes, auto-afirmativas e cônscias de seus direitos - por meio de militância que em muito antecede a problemática da própria epidemia - seja absolutamente diversa daquela de homens que fazem com outros homens inseridos em outros contextos culturais, como em cidades de menor porte, em comunidades de maioria latina nos países anglo-saxônicas ou comunidades faveladas em países como o Brasil (Parker \& Camargo Jr., neste fascículo).

Portanto, os obstáculos estruturais postos ao exercício dos direitos humanos e as perspectivas de sua superação são simultaneamente frutos de uma estrutura e de processos sociais em contínua reformulação, do qual somos todos partícipes. Para além da própria epidemia de HIV/ AIDS, lidamos aqui com um conjunto de reflexões e ações que se confunde com a busca permanente da humanidade por liberdade, justiça e dignidade.

\section{Referências}

BASTOS, F. I., 1996. Ruína \& Reconstrução. AIDS e Drogas Injetáveis na Cena Contemporânea. Rio de Janeiro: Editora Relume-Dumará/ ABIA/IMS-UERJ.

BOILY, M. C. \& ANDERSON, R. M., 1996. Human immunodeficiency virus transmission and the role of other sexually transmitted diseases. Measures of association and study design. Sexually Transmitted Diseases, 23:312-332.

CELENTANO, D. D.; VLAHOV, D.; COHN, S.; SHADLE, V. M.; OBASANJO, O. \& MOORE, R. D., 1998. Selfreported antiretroviral therapy in injection drug users. JAMA, 280:544-546.

CHIRIBOGA, C. R., 1997. Introducción. Mujer y SIDA: Conceptos sobre el tema. In: Situación delas Mujeres y el VIH/SIDA en América Latina (B. Rico, S. Vandale, B. Allen \& A. L. Liguori, eds.), p. 22, Cuernavaca: Instituto Nacional de Salud Pública. 
COLL, O.; VIDAL, R.; MARTINEZ-DE-TEJADA, B.; BALLESCA, J. L.; AZULAY, M. \& VANRELL, J. A., 1999. Management of HIV serodiscordant couples. The clinician point of view. Contraception, Fertilité, Sexualité, 27:399-404.

DESJARLAIS, D. C. \& FRIEDM AN, S. R., 1998. Fifteen years of research on preventing HIV infection among injecting drug users: What we have learned, what we have not learned, what we have done, what we have not done. Public Health Report, 113 (Sup. 1):182-188.

ELIAS, C. J. \& COGGINS, C., 1996. Female-controlled methods to prevent sexual transmission of HIV. AIDS, 10 (Sup. 3):S43-51.

ENG, T. R. \& BUTLER, W. T., 1997. The Hidden Epidemic. Washington, D.C.: National Academy Press.

FARMER, P., 1996. Social inequalities and emerging infectious diseases. Emergent Infectious Diseases, 2:259-269.

FARMER, P., 1997. Social scientists and the new tuberculosis. Social Science and Medicine, 44:347-3458.

FONSECA, M. G. P. \& CASTILHO, E. A., 1997. Os casos de AIDS entre usuários de drogas injetáveis. Brasil, 1980-1997. Boletim Epidemiológico - AIDS, $\mathrm{X}: 6-14$.

FRIEDMAN, S. R.; SOTHERAN, J. L.; ABDUL-QUADER, A.; PRIMM M B. J.; DES JARLAIS, D. C.; KLEINMAN, P.; MAUGE, C.; GOLDSMITH, D. S.; EL-SADR, W. \& MASLANSKY, R., 1987. The AIDS epidemic among blacks and Hispanics. Milbank Quarterly, 65 (Sup. 2):455-499.

FRIEDMAN, S. R.; JOSE, B.; DEREN, S.; DES JARLAIS, D. C. \& NEAIGUS, A., 1995. Risk factors for human immunodeficiency virus seroconversion among out-of-treatment drug injectors in high and low seroprevalence cities. The National AIDS Research Consortium. American Journal of Epidemiology, 142:864-874.

FRIEDMAN, S. R.; FURST, R. T.; JOSE, B.; CURTIS, R.; NEAIGUS, A.; DES JARLAIS, D. C.; GOLDSTEIN, M. F. \& ILDEFONSO, G., 1998. Drug scene roles and HIV risk. Addiction, 93:1403-1416.

GIFFIN, K. \& LOWNDES, C. M., 1999. Gender, sexuality, and the prevention of sexually transmissible diseases: A Brazilian study of clinical practice. Social Science and Medicine, 48:283-292.

GRANGEIRO, A., 1994. O perfil sócio-econômico da AIDS no Brasil. In: A AIDS no Brasil (R. Parker, C. Bastos, J. Galvão \& S. Pedrosa, ed.), pp. 91-128, Rio de Janeiro: ABIA/UERJ/Editora Relume-Dumará.

GREENLAND, S.; LIEB, L.; SIMON, P.; FORD, W. \& KERNDT, P., 1996. Evidence for recent growth of the HIV epidemic among African-American men and younger male cohorts in Los Angeles County. Journal of Acquired Immune Deficiency Syndromes and Human Retrovirology, 11:401-409.

GRUND, J. P.; STERN, L. S.; KAPLAN, C. D.; ADRIAANS, N. F. \& DRUCKER, E., 1992. Drug use contexts and HIV-consequences: The effect of drug policy on patterns of everyday drug use in Rotterdam and the Bronx. British Journal of Addiction, 87:381-392.

GUPTA, S.; ANDERSON, R. M. \& MAY, R. M., 1989. Networks of sexual contacts: Implications for the pattern of spread of HIV. AIDS, 3:807-817.
HOGG, R. S.; STRATHDEE, S. A.; CRAIB, K. J.; O'SHAU GHNESSY, M. V.; MONTANER, J. S. \& SCHECHTER, M. T., 1994. Lower socioeconomic status and shorter survival following HIV infection. Lancet, 344:1120-1124.

HOGG, R. S.; WEBER, A. E.; CRAIB, K. J.; ANIS, A. H.; O'SHAU GHNESSY, M. V.; SCHECHTER, M.T. \& MONTANER, J. S., 1998. One world, one hope: The cost of providing antiretroviral therapy to all nations. AIDS, 12:2203-2209.

ISLAM, M.; MITRA, A. K.; MIAN, A. H. \& VERMUND, S. H., 1999. HIV/ AIDS in Bangladesh: A national surveillance. International Journal of STD and AIDS, 10:471-474.

KASS, N. E.; MUÑOZ, A.; CHEN, B.; ZUCCONI, S. L. \& BING, E. G., 1994. Changes in employment, insurance, and income in relation to HIV status and disease progression. The Multicenter AIDS Cohort Study. Journal of Acquired Immune Deficiency Syndromes, 7:86-91.

KRIEGER, N., 1994. Epidemiology and the web of causation: Has anyone seen the spider? Social Science and Medicine, 39:887-903.

LECLERC-M ADLALA, S., 1997. Infect one, infect all: Zulu youth response to the AIDS epidemic in South Africa. Medical Anthropology, 17:363-380.

LURIE, P.; HINTZEN, P. \& LOWE, R. A., 1995. Socioeconomic obstacles to HIV prevention and treatment in developing countries: The roles of the International Monetary Fund and the World Bank. AIDS, 9:539-546.

MALES, M., 1996. AIDS and ethnicity. Science, 271: 1479-1480.

MANN, J. M., 1998. AIDS and human rights: Where do we go from here? Health and Human Rights, 3:143-149.

MANN, J. M. \& TARANTOLA, D., 1996. AIDS in the World II. New York/Oxford: Oxford University Press.

MASSEY, D. S., 1996. The age of extremes: Concentrated affluence and poverty in the twenty-first century. Demography, 33:395-412.

MATTOS, R., 1999. Sobre os limites e as possibilidades dos estudos acerca dos impactos das políticas públicas relativas à epidemia de HIV/AIDS: Algumas reflexões metodológicas feitas a partir do caso brasileiro. In: Saúde, Desenvolvimento e Política: Respostas frente à AIDS no Brasil (R. Parker, J. Galvão \& M. S. Bessa, ed.), pp. 29-90, São Paulo: Editora 34.

MBOI, N., 1996. Women and AIDS in South and South-East Asia: The challenge and the response. World Health Statistics Quarterly, 49:94-105.

MCMILLAN, S., 1996. AIDS and ethnicity. Science, 271:1480.

MONGELLA, G., 1995. Global approaches to the promotion of women's health. Science, 269:789-790.

MORRIS, M.; ZAVISCA, J. \& DEAN, L., 1995. Social and sexual networks: Their role in the spread of HIV/ AIDS among young gay men. AIDS Education and Prevention, 7 (Sup.):24-35.

PINHO, M. D. G., 1998. Vulnerabilidade da população negra ao HIV/AIDS. In: População Negra em Destaque(E. Berquó, ed.), pp. 56-58, São Paulo: Centro Brasileiro de Estudos Populacionais.

ROSENBERG, P. S., 1995. Scope of the AIDS epidemic in the United States. Science, 270:1372-1375. 
SANT'ANNA, W., 1998. IBGE e a nova classificação racial. Decifra-me ou te devoro. In: População Negra em Destaque (E. Berquó, ed.), pp. 42-48, São Paulo: Centro Brasileiro de Estudos Populacionais.

SINGER, M., 1994. AIDS and the health crisis of the U.S. urban poor: the perspective of critical medical anthropology. Social Science and Medicine, 39:931-948.

STRATHDEE, A. S.; PALEPU, A.; CORNELISSE, P. G. A.; YIP, B.; O'SHAUGHNESSY, M. V.; MONTANER, J. S.; SCHECHTER, M. T. \& HOGG, R. S., 1998. Barriers to use of free antiretrovirals therapy in injecting drug users. JAMA, 280:547-549.

SZWARCWALD, C. L.; BASTOS, F. I.; GRAVATO, N.; LACERDA, R.; CHEQUER, P. N. \& CASTILHO, E. A., 1998. The relationship of illicit drug consume to HIV-infection among commercial sex workers (CSWs) in the city of Santos, São Paulo, Brazil. International Journal of Drug Policy, 9:427-436.

TAWIL, O.; VERSTER, A. \& O'REI LLY, K. R., 1995. Enabling approaches for HIV/AIDS prevention: Can we modify the environment and minimize the risk? AIDS, 9:1299-1306.

TELLES, P. R.; BASTOS, F. I.; GUYDISH, J .; INCIARDI, J. A.; SURRAT, H.; PEARL, M. \& HEARST, N., 1997. Risk behaviors and HIV seroprevalence among IDUs in Rio de Janeiro, Brazil. AIDS, 11 (Sup. 1): S35-S44.

VAN DAM ME, L. \& ROSENBERG, Z. F., 1999. Microbicides and barrier methods in HIV prevention. AIDS, 13 (Sup. A):S85-S92.

VICTORA, C. G.; HUTTLY, S. R.; FUCHS, S. C. \& OLINTO, M. T. A., 1997. The role of conceptual frameworks in epidemiological analysis: A hierarchical approach. International Jounal of Epidemiology, 26:224-227.
WALLACE, R. \& WALLACE, D., 1995. U.S. apartheid and the spread of AIDS to the suburbs: A multicity analysis of the political economy of spatial epidemic threshold. Social Science and Medicine, 41:333-345.

WALLACE, R.; FULLILOVE, M. T. \& FLISHER, A. J., 1996. AIDS, violence and behavioral coding: Information theory, risk behavior and dynamic process on core-group sociogeographic networks. Social Science and Medicine, 43:339-352.

WALLACE, R.; HUANG, Y. S.; GOULD, P. \& WALLACE, D., 1997. The hierarchical diffusion of AIDS and violent crime among U.S. metropolitan regions: Inner-city decay, stochastic resonance and reversal of the mortality transition. Social Science and Medicine, 44:935-947.

WEIDLE, P. J .; HOLMBERG, S. D. \& DECOCK, K. M., 1999. Changes in HIV and AIDS epidemiology from new generation antiretroviral therapy. AIDS, 13 (Sup. A):S61-S68.

WODAK, A., 1998. Health, HIV Infection, human rights, and injecting drug use. Health and Human Rights, 2:24-41.

WONG, G. Y. \& MASON, W. M., 1991. Contextually specific effects and other generalizations of the hierarchical linear model for comparative analysis. Journal of the American Statistical Association, 86:487-503.

YEN, I. H. \& SYME, S. L., 1999. The social environment and health: A discussion of the epidemiologic literature. Annual Review of Public Health, 20:287-308.

ZIERLER, S. \& KRIEGER, N., 1997. Reframing women's risk: Social inequalities and HIV infection. Annual Review of Public Health, 18:401-436. 